Andrew Iliadis:

\title{
The Right to Nonparticipation for Global Digital Citizenship
}

\begin{abstract}
:
This article argues for the right to nonparticipation for Global Digital Citizenship (GDC). It recuperates the notion of political nonparticipation in the context of information and communication technologies (ICTs) and GDC in order to show that nonparticipation can operate effectively in non-State spheres, particularly online. The paper begins with a discussion of nonparticipation in the context of Nation States and non-Statal Organizations before offering a brief survey of the terms Global Citizenship (GC), Digital Citizenship (DC), and GDC. Nonparticipation in an online context is then explained, followed by a discussion of practical concerns, such as who might enforce GDC rights among global digital citizens.
\end{abstract}

\section{Agenda:}

Introduction

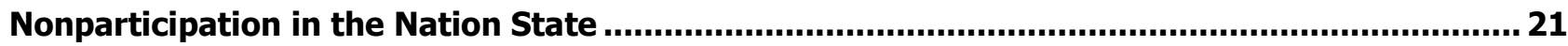

Nonparticipation in Non-Statal Organizations ................................................................... 22

Towards a Definition of Global Digital Citizenship ............................................................... 24

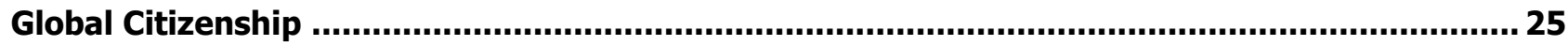

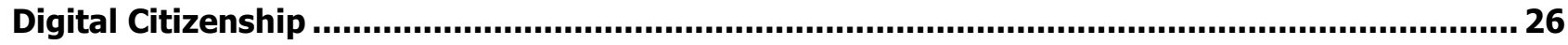

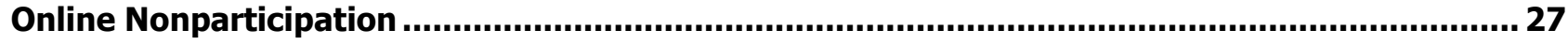

Towards a Policy for Global Digital Citizenship ................................................................... 28

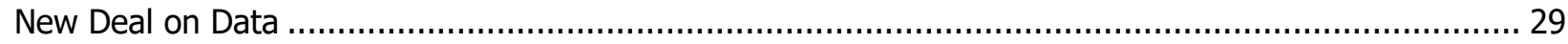

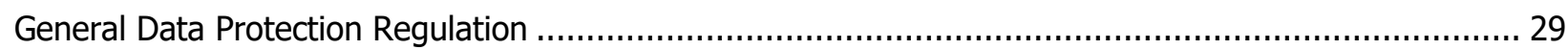

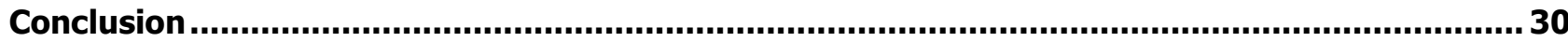

\section{Author:}

Andrew Iliadis:

- Doctoral Candidate, Purdue University, Brian Lamb School of Communication, Beering Hall of Liberal Arts and Education, Room 2114, 100 N. University Street, West Lafayette, IN, 47907-2098, USA, Main

- 甶 + (765) 494-3429, $\bowtie$ ailiadis@purdue.edu 


\section{Introduction}

That today's internet policy debates should turn to focus on the rights of data subjects is indicative of where the Internet stands in relation to citizenship. In her introduction to the inaugural issue of the journal Policy \& Internet, Margetts (2009) offered several normative values traditionally associated with the Internet, including innovation, trust, openness and equity, "that might be expected to emerge in policy trends" (p. 1). The Internet has, unsurprisingly or not, headed in the opposite direction, with less generativity (Zittrain, 2008), decreased trust (Cerf, 2010), censorship (Depken, 2006), and digital divides (Gunkel, 2003). Part of the reason for this is the appearance of non-Statal organizations (Floridi, 2014) which do not treat individuals as citizens or data subjects, yet which are allowed to maintain authoritative rights over their data much in the same way as traditional Nation States. Rather, such organizations tend to treat individuals as reserves of data capital (Yousif, 2015). It is at the intersection of citizenship and data capital that something like a right to nonparticipation can act as protection against future data exploitation. However, while privacy and surveillance are regularly studied in relation to information and communication technologies (ICTs), the concept of nonparticipation remains an understudied area of research.

The right to nonparticipation can serve as an ideal barometer of the quality of privacy measures taken by nonStatal organizations to protect against data capital exploitation. Further, future policy work will be in revisiting the notion of citizenship in light of such practices. What is new about nonparticipation in light of ICTs is that users are no longer comfortable giving up their data in exchange for services. A recent survey conducted at the Annenberg School for Communication found that "marketers are misrepresenting a large majority of Americans by claiming that Americans give out information about themselves as a tradeoff for benefits they receive. To the contrary, the survey reveals most Americans do not believe that 'data for discounts' is a square deal" (Turow, Hennessy, \& Draper, 2015, p. 3). As such, the growth of online ICTs and data capture techniques poses a new set of problems for privacy, citizenship, and nonparticipation. Citizen nonparticipation in the Nation State is different from nonparticipation online, possibly opening nonparticipation as a viable alternative to readymade options in the digital sphere. Active nonparticipation can be a useful tool in non-State domains where conceptualizations of what counts towards citizenship changes (May 2012). Since digital surveillance "is an everyday experience, run by myriad agencies for multiple purposes and exempting no one" (Lyon, 2002), the right to nonparticipation is one way of protecting the rights of data subjects against non-Statal organizations.

\section{Nonparticipation in the Nation State}

Nonparticipation in the context of democratic electoral politics has long been criticized as hindering change and ultimately slowing down political progress (Arnstein, 1969). Nonparticipating citizens are often vilified and nonparticipation is viewed as an extreme political practice, one that (though extreme) has proved to have little political effect (Soss \& Jacobs, 2009). Typically, nonparticipation in the democratic Nation State serves as a final attempt to demonstrate disagreement with government when remaining participatory options are considered unsatisfactory. The nonparticipating individual might, for example, refrain from voting in an election when none of the proposed candidates are viewed as sufficiently qualified. In this context, nonparticipation is a 'silent' act that does not facilitate change in the political process but rather serves to highlight the discontent of individual actors. For all its defiant posturing, nonparticipation is somewhat of a non-answer in an electoral democratic politics where participation in the affairs of the Nation State has traditionally been viewed as a requisite for democracy (Lipset, 1959). Nonparticipation runs anathema to the ideological underpinnings of the democratic Nation State, which has depended on effective citizen participation since the days of ancient Athenian politics (Robinson, 2011). Negative connotations traditionally associated with nonparticipation today are premised on a "widespread concern about declining levels of political engagement and participation," particularly among young people (O'Toole, Marsh, \& Jones, 2003, p. 349). The assumption is that nonparticipation is closely aligned with apathy, not politics, and that this is a hindrance to democracy. 
On closer examination, nonparticipation has deep roots in the arena of politics, particularly in nonviolent movements (Kurlansky, 2006) and legal contexts (Harrington, 1984). Further, acts of symbolic nonparticipation are politically charged, fairly common, and have been practiced with regularity throughout history. Jean-Paul Sartre's refusal to accept the Nobel Prize for Literature is one famous example. Symbolic nonparticipation can be found too in mundane, everyday moments of subtle discontent that are sometimes barely registered, such as when one chooses to boycott a specific product or corporation (Klein, Smith, \& John, 2004). When an individual refuses to stand during a national anthem - as the National Basketball League's Mahmoud AbdulRauf did when he declined to stand for the Star-Spangled Banner during pregame ceremonies (Diamos, 1996) - it is also an act of political and symbolic nonparticipation. Yet, apart from such visible instances of symbolic nonparticipation, the longstanding popular conception of political nonparticipants views them as apathetic individuals who do not fully appreciate the function of government (Hastings, 1956). Those individuals who do engage nonparticipation as a specifically political act in the context of the democratic Nation State are rarely noticed compared to the allegedly apathetic, nonparticipating youth.

While there is admittedly some truth to the claim that nonparticipation can, in certain cases, be the result of apathy, more attention should be paid to the ways in which nonparticipation may function as an explicitly political act, both inside and outside of the context of the Nation State. To associate nonparticipation only with apathy is to miss the multitude of ways that nonparticipation can be used as a political tool or viewed as an indication of deeper, structural problems inherent to a democracy. Citizens of a Nation State, for example, may turn to nonparticipation due to their unrepresentation in government (Han, 1970). If there is no one to represent the interests of a specific group of citizens in the political apparatus then those same citizens remain politically preindividuated (Simondon, 2005) in the eyes of the Nation State-they fail to be recognized as an individual group. In this context, apathy can hardly be used as an excuse to justify the dismissal of such nonparticipating individuals. Nonparticipation can accomplish more and bring about change for an un(der)represented group if it is rethought as a symptom of unfairness. Further, civic participation outside of political spheres can push individuals to be more politically active (Jeong, 2013). As E. E. Schattschneider wrote, in The Semi-Sovereign People (1960):

It is profoundly characteristic of the behavior of the more fortunate strata of the community that responsibility for widespread nonparticipation is attributed wholly to the ignorance, indifference and shiftlessness of the people. This has always been the rationalization used to justify the exclusion of the lower classes from any political system. There is a better explanation. Abstention reflects the suppression of the options and the alternatives that reflect the needs of the nonparticipants. It is not necessarily true that the people with the greatest needs participate in politics most actively. Whoever decides what the game is about decides also who can get into the game (p. 104-105).

Schattschneider's important observation is that nonparticipation might reflect the absence of alternatives for nonparticipating citizens. In the Nation State, citizen nonparticipation may occur due to the continuing existence of social or political barriers that prevent citizens from participating. Here, nonparticipation should be viewed as a potential symptom of some of the underlying structural problems that can exist outside current instantiations of democratic politics (e.g. underrepresentation). The difficulty, of course, is that in a politics where participation is the order of the day, nonparticipation is viewed as an evil and not a legitimate source for reflection or opportunity for political progress. Citizens of the Nation State may experience difficulty in changing the perception of nonparticipation for this reason-the democratic Nation State demands the active participation of its citizenry in politics. Citizens remain bound to the rules of participatory democracy as long as they are part of the Nation State, and this places the act of nonparticipation in a precarious position with regard to available (and viable) political options.

\section{Nonparticipation in Non-Statal Organizations}

The legitimacy of political nonparticipation is intimately tied to the concept of citizenship. While citizens of the Nation State may experience varying degrees of success in turning nonparticipation into an opportunity for 
political progress, there are alternative forms of citizenship currently under debate that can successfully integrate a politics of nonparticipation into their modes of existence (Latour, 2013) and where nonparticipation may be viewed as a fundamental right. Might nonparticipation one day be raised to the level of influencing policy alternatives? Unlike citizens of the Nation State who are tied to citizenship and held to national laws on condition that democracy can successfully function, policy debates are growing around new forms of citizenship that are emerging on the Internet (Isin \& Ruppert, 2015), in the context of global surveillance capitalism (Zuboff, 2015), which do not have a stake in or claim to any such national entity or appeal to democracy (Berkeley's recently launched Center for Technology, Society \& Policy lists 'digital citizenship' as one of its focus areas).

Increasingly, citizens are expected to engage participatory action in the shape of new digital practices and with online, non-Statal organizations in place of similar bureaucratic commitments in the context of the Nation State (the issuing of birth certificates, voting, etc.). The difference lies in this. Instead of participating in the democracy of the Nation State, new types of citizens are forced to participate in the digitality (Baudrillard, 2006) of non-Statal organizations each time they are online by offering up their data. Further, it remains increasingly difficult for citizens to 'opt out' (Vleugels, Verhenneman, \& Bannier, 2011) of digitality given the importance of digital ICTs for work and other essential, everyday activities (Purcell \& Rainie, 2014). Following the 1998 Data Protection Act and the European Data Protection Supervisor, such citizens are now referred to as data subjects-individual's whose data is recorded when they are online.

Three significant differences might be considered in the active relationships between citizens in the Nation State and those who engage (or are engaged by) non-Statal organizations.

First, both versions of participatory action (Statal and non-Statal) involve individuals giving up personal information in the form of online data or metadata. Yet, that individuals often consent to data capture by virtue of agreeing to Terms of Service (ToS), End-User License Agreements (EULAs), and Privacy Policy (PP) statements provided by non-Statal organizations should not waive the rights of individuals over their data, since it remains questionable to what degree individuals are able to meaningfully interpret most ToS, EULA, and PP statements. Chee, Taylor, and de Castell (2012) find that many users "confirmed that they simply clicked through the terms presented to them without much knowledge about the terms to which they were agreeing" (p. 497). Further, Custers, van der Hof, and Schermer (2014) note that social media users generally "do not read privacy policies and show low levels of acceptance and significant dissatisfaction with current practices and policies" (p. 291). Users often 'consent' to legal agreements even though they might not read, trust, or fully understand them.

The more important point in the difference between Nation States and non-Statal organizations is that information is voluntarily given by citizens (excluding illegal government spying) in the context of the democratic Nation State, while in the context of non-Statal organizations information is often surreptitiously extracted. Control of what constitutes public and private data then ends up falling under the purview of the non-Statal organization. Radu and Chenou (2015) argue that "data control, among the newest forms of power fostered by [...] (ICTs), triggers a continuous (re)negotiation of public and private orderings, with direct implications on both regulators and intermediaries" (p. 1). Non-Statal organizations' control of data is a form of power over the data subject, an inversion of the ideal relationship between citizen and government. For example, individuals do not simply hand over their data in social media profiles like Facebook or Twitter. It is gathered in increments over a long period of time.

Second, where participatory action in the form of voluntary information disclosure (by way of vote, census, and so on) for the improvement of the social is the historical raison d'être of the Nation State, this can hardly be the case for online, non-Statal organizations where the primary underlying motivations are for profit. Individuals are treated as consumers rather than as citizens, yet consumer protection rights often fail. This is reflected in EULAs that are unfair, particularly in "the imbalance between user and developer interests governed by such contracts" that often "cannot be regulated with consumer protection legislation, as interests such as property or intellectual property are beyond the scope of consumer protection regimes" (Harbinja, 
2014, p. 1). As Harbinja (2014) notes, a more appropriate course of action is to treat such individuals as citizens who have rights, rather than as consumers. The new citizens that have emerged in this context may be referred to as global digital citizens - online individuals who are forced to participate in information disclosure by non-Statal organizations simply by virtue of engaging digitality - and should be conceptualized differently from traditional citizens of the Nation State.

Lastly, the familiar arguments that so much social media data are already public or that individuals who have nothing to hide should not be concerned about non-Statal organizations' control of data are poor ones to make, as observed by Zimmer (2010) and Solove (2007). The problem, Solove writes, is "the underlying assumption that privacy is about hiding bad things. Agreeing with this assumption concedes far too much ground and leads to an unproductive discussion of information people would likely want or not want to hide" (2007, p. 764). The problem of information privacy and its solution depend "upon how these privacy problems are conceptualized" (Solove, 2004, p. 6). A decade since Solove's observation, the question of information privacy and the conceptualization of it remain somewhat unclear. In The Digital Person (2004), Solove states that "we have little power or say" within bureaucratic ICT systems, which tend "to structure our participation along standardized ways that fail to enable us to achieve our goals, wants, and needs" (p. 39) -the argument is one defined in terms of participation over nonparticipation.

Arguments in favor of more participation have a long history in discussions of information privacy (Schwartz, 1994). One might suggest increased participation as a remedy to corporate overreach over an individual's data, yet emphasis should instead be placed on nonparticipation as an a priori rule. Participation, while useful in the context of the Nation State, remains somewhat conceptually insufficient for thinking about global digital citizenship and the nature of informational capital (Bourdieu, 1994). The problem of privacy may be better conceptualized through the lens of nonparticipation as opposed to participation, since participation presupposes that information extracted from data subjects is unavoidable, an epiphenomenon of being online, when the opposite is the case. It takes effort and resources to track digital footprints. Like the Nation State, one of the powers of non-Statal organizations is to create and sustain a social mythos about its operations, including narratives about the naturalness of data surveillance.

\section{Towards a Definition of Global Digital Citizenship}

The Internet consistently demands that individuals actively give up their data to non-Statal organizations. Like the Nation State, the Internet's non-Statal organizations demand active participation, only in a different way and for different purposes, most of them financial rather than political.

There is a large body of policy research on active participation and the alternative forms of citizenship that have emerged after the widespread use of the Internet. Much of it focuses on the terms Global Citizenship (GC) and Digital Citizenship (DC), yet neither should be conflated with traditional citizenship in the Nation State or with each other. A closer look at their definitions will show that GC and DC can be interpreted differently depending on the context and that neither is entirely sufficient to describe the new forms of citizens that have emerged 'onlife' (Floridi, 2015)-where the distinction between life online and offline becomes blurred. The combined term Global Digital Citizenship (GDC) should be preferred since it implies a global citizen who is online, not connected to the Nation State, and open to the participatory threat of involuntary information disclosure by non-Statal organizations. It will be useful to provide a definition of GDC here before moving forward. 
def. Global Digital Citizenship:

A type of online citizenship, not connected to the Nation State but connected to non-Statal organizations, that is global in nature and where the right to nonparticipation is a primary right.

The right to nonparticipation belongs to GDC in that, like the Nation State, GDC calls for citizens to participate, however this participation is not ideally legitimate in the same way that it is represented in the relationship between citizen and government in the Nation State. First, non-Statal organizations do not require participation as a fundamental condition for their existence. Second, non-Statal organizations are not constituted by global digital citizens (in the same way that citizens may constitute the Nation State). Non-Statal organizations constitute themselves and serve no representative function. Thus, GDC is not concerned with the Nation State or with representation as such, but rather with the globalized pressure of online participation.

\section{Global Citizenship}

GDC should be preferred over GC and DC, which are becoming stale. GC is generally viewed as the global duty of world citizens to contribute to the development of human rights across territorial boundaries-thus it maintains a modicum of respect for traditional Nation States (Cabrera, 2010). The struggle with national boundaries remains a problem for GC policy researchers due to the difficulty of combining a higher level duty to GC with the continued rights and practices of traditional Nation States. Indeed, some policy researchers argue that it is not a matter of combining the two approaches but rather a question of choosing the right option (in this case, GC). Clark (2010) writes that GC involves a choice between a "global community under a rule of international law (Option $A$ ) or ongoing violent contests for power driven by militant nationalism (Option $B)^{\prime \prime}(p$. $20)$. GC has also been generally described as "the growing consciousness that globalization entails new kinds of questions for political membership, global responsibilities for the future and new conceptions of personhood" (O'Byrne, 2003, p. ix). Others suggest - contra Clark (2010) - that GC "does not operate in contradiction with regional, national and local identities. It expresses itself through them" (Hoffman, 2004). GC is a contested term among researchers, yet the common thread running through the many definitions of GC views it as operating in a world where there are two levels of duty, one local (national government), the other global (global rights). The problem is a longstanding one that continues to complicate conceptualizations of GC.

Nevertheless, GC proposals have been institutionally enacted within the boundaries of international organizations such as the United Nations and Amnesty International. A focus on such institutional branches of GC shows that it can be applied differently in varying contexts, including corporate global citizenship (Tichy, McGill, \& St. Clair, 1997), human rights and global citizenship (Abdi \& Shultz, 2008), environmental challenges and global citizenship (Hillerbrand \& Karlsson, 2008), justice and global citizenship (Haugestad \& Wulfhorst, 2004), social movements and global citizenship (McIntyre-Mills, 2005), youth and global citizenship (Collins, 2008), post-colonialism and global citizenship (Andreotti \& de Souza, 2012), and political theory and global citizenship (Carter, 2001). As such, GC remains a plural concept that is open to the threat of oversaturation. Tully (2014) speaks to the diverse definitions and applications of the term 'global citizenship':

The art of understanding a concept like 'global citizenship' is not the application of a universal rule to particular cases. Rather, the uses of such complex concepts in different cases and contexts do not have one set of properties in common, but - from case to case - an indeterminate family of overlapping and crisscrossing 'similarities, relationships, and a whole series of them at that'. What 'we see', therefore, is not a single rule (definition or theory) being applied in every case, but, rather, 'a complicated network of similarities overlapping and crisscrossing: sometimes overall similarities, sometimes similarities of detail'. (p. 4-5).

Tully's distinction that GC concerns "an indeterminate family of overlapping and crisscrossing" similarities and relationships is indicative of the potential oversaturation of the term. It could conceivably be argued that GC 
has existed since at least as long as globalization itself and that therefore it is a concept that has been put to work in every context where globalization plays an influential role.

Additionally, GC implies that nonparticipation may not be a suitable political option given the way in which some proponents of GC view it as an overarching connective tissue on top of traditional citizenship in the Nation State. As such, GC can involve cross-border privacy issues (Svantesson, 2011) that are difficult to resolve. In the large majority of cases, GC involves something like a supracitizen who is still anchored to citizenship in the Nation State. One might still have to participate at the level of national citizenship in order to access and be a part of GC. This, however, would complicate the nature of nonparticipation, which should be a fundamental right for online citizens who are forced to participate by non-Statal organizations. Since GC depends on the practices of traditional citizenship in the Nation State, it is implied that GC too is a participatory type of citizenship. Second, if GC is to be conceptualized instead as acting in place of citizenship in the Nation State, then it would be simply be a matter of transferring all of the local functions of citizenship in the Nation State to the Global State, including active participation. Thus, participation remains in both iterations of GC, which is unacceptable.

\section{Digital Citizenship}

Contemporary globalization itself is the product of diverse ICTs that are beginning to change the ways in which citizenship is conceptualized. The term "digital citizens" was created to refer to emerging groups of online citizens, "the most informed and participatory citizens we ever had or are likely to have" after the Digital Revolution (Katz, 1997). Today, DC is a much more useful concept when thinking about the increasingly globalized nature of citizenship. DC may sometimes connote a practice that has more in common with teaching online participation and digital decorum rather than with practicing politics per se (Ribble \& Bailey, 2011). In other contexts, it concerns itself with information literacy (Kurbanoğlu et al, 2014) and participation (Mossberger, Tolbert, \& McNeal, 2008), thus some versions of DC do lend well to the idea of nonparticipation.

Alternative forms of DC prove it to be a much more useful concept than GC for discussing the type of rights that are owed to citizens given its focus on the rights claims of digital citizens over its conceptualization of their positionality in terms of international and national duty. Isin and Ruppert (2015) pinpoint this distinction. They ask "how do subjects act in ways that transgress the expectations of and go beyond specific conventions and in doing so make rights claims about how to conduct themselves as digital citizens?" (p. 5). The focus is on how DC makes rights claims via the Internet. The idea is to move from a citizenship that is forced to be active by the Nation State to one that posits self-activity as its mode of being. Citizens in DC "enact themselves as citizens by negotiating their rights such as privacy, access, openness, and innovation and their rights concerning data" (Isin \& Ruppert, 2015, p. 5). The focus is on whom the subject of these rights is, who may constitute themselves as a digital subject through the Internet.

In this iteration of DC, then, the digital citizen is a figure who makes rights claims via the Internet. DC here is experiential, embodied, and activated through the Internet. The citizen is not "a bearer or recipient of rights that already exist but one whose activism involves making claims to rights that may or may not exist" (Isin \& Ruppert, 2015, p. 9). This point is important since the citizen is theorized as actively invoking their rights rather than merely seeking to apply preexisting rights, as in GC. Nonparticipation may be compatible here since it can be conceptualized as one of the new rights claims made by DC. Yet, the focus on making positive rights claims does not entirely suit the right to nonparticipation. The right to nonparticipation is the right to refuse to engage the non-Statal organization rather than come to a compromise with it.

GDC may be used to define the types of citizens that are found online and who are owed a new set of rights, including the right to nonparticipation. Current investigations into what it means to be a human online and the construction of digital manifesto repositories are beginning the inquest into the types of rights that are owed to global digital citizens. Most importantly, GDC can lend itself to nonparticipation since it does not exist, in any significant way, in a relationship with citizenship in the Nation State (GC) or active participation with non- 
Statal organizations (DC). Where GC remains tied to the Nation State and DC recommends active participation with non-Statal organizations, GDC recommends that individuals should be given the right to refuse to participate in any digital activities, including online data collection, even though such individuals may remain online in perpetuity. Nonparticipation on the Internet is already a fairly common practice (for example, using software such as Tor to communicate anonymously online), and individuals who engage such practices may be thought of as enacting a form of GDC.

\section{Online Nonparticipation}

Where nonparticipation is typically seen as a fringe political practice by citizens of the Nation State, nonparticipation in online domains should be viewed as one of the most important rights of GDC given the extent to which information about online data collecting is concealed from global digital citizens in favor of ever-expanding algorithmic control (McKelvey, 2014). In an era of governance by algorithms (Musiani, 2013), nonparticipation should be viewed as a right that protects global digital citizens against data capture, surveillance capitalism, and the (imperfect, illegitimate) algorithmic governance of non-Statal organizations.

In order to nurture nonparticipation as an available political option, broad and constant notifications on websites and social networking programs might indicate the types of information that will be gathered from individuals, much in the same way that closed circuit television camera (CCTV) notices inform the public that they are being video recorded in public spaces; such is the minimum notice afforded by state surveillance in the right to privacy (Taylor, 2002). Similarly, notifications that explain the relevance of algorithms (Gillespie, 2014) can be made easily accessible and transparent in the same way nutrition information is clearly labeled on food packaging so that global digital citizens may have access to literature regarding the organization of their information. The option to nonparticipation should be made clear in each circumstance and individuals should be told what information will be collected from them up front rather than provided with lengthy and labyrinthine ToS, EULA, and PP statements. Global digital citizens deserve the right to nonparticipation when it comes to the mining and scraping of data that is considered important to them, yet little attention is paid to nonparticipation in an online context.

Perhaps unsurprisingly, it is common to find websites which do not allow users to control privacy functions (a potentially important tool in the right to nonparticipation). Why is this so? Park (2014) analyzed "user control of privacy online as indicated by functional features of commercial websites" (p. 360) and found that many of the sites did not allow users to easily control their data:

In idealized digital spheres, users should be able to exercise privacy control by easily finding how information about them is collected, retained, and processed. Further, they should be able to post questions or responses to the policy they find questionable and engage with others through interactive links and features connected to the sites. Yet at present, the commercial websites function as a one-way surveillance platform, largely closed in interface constraints, with limited provision of interactive links and features. Simply put [...] the platform with the interface channel that allows users to freely exercise control does not exist (p. 371).

The idea here is that there are fewer ways for global digital citizens to control their own data and how it is recorded online. In contrast to this, non-Statal organizations might adopt the common practice of using the right to nonparticipation as a baseline construct to determine if their platform is sufficiently ethical for global digital citizens. As Agre (1999) observed, data protection "may provide guidance for institutional design [...] the promotion of privacy-enhancing technologies should aim to incorporate them into the design of institutions generally and market intermediaries in particular" (p. 20). The right to nonparticipation can be a benchmark theoretical construct for the building of online ICT platforms, integrating privacy measures against data capture into user experience and design. In this respect, the right to nonparticipation should be seen not merely as a reactive rights claim. Rather, it can be used to actively construct and enforce technological design. In some 
cases this is already happening. For example, data ownership and portability was a key design element in the launch of Google+ in 2011 (Pentland, 2014).

While the right to nonparticipation for GDC is a fight against data surveillance it should not be confused with the right to hide (Monahan, 2015) and similar privacy movements which tend to ignore the illegitimacy of apparatuses of data capture in favor of a focus on protecting the individual user. Rather, the right to nonparticipation questions the legitimacy of the apparatus first. Global digital citizens deserve the right to nonparticipation when they are engaged in online activities where virtually every ICT produces data about its users. Data and metadata about users - their location, timestamps, duration, etc. - should be optional and at the discretion of the user so that they can preemptively avoid legal disputes over their data.

Various reactive measures to evade data capture have appeared. Some obscure faces from facial recognition software-the website CV Dazzle (http://cvdazzle.com/) "explores how fashion can be used as camouflage from face-detection technology, the first step in automated face recognition." Others develop custom scripts to successfully delete user profiles and data from social networking sites. Justdeleteme.me is "a directory of direct links to delete your account from web services" (http://justdelete.me/). The website grades a multitude of online services and how difficult it is to successfully delete user information. 'Easy' means a simple process, 'medium' means extra steps, 'hard' means that the account cannot be fully deleted without contacting customer services, and 'impossible' means that the account cannot be deleted. YouTube, Wikipedia, and Wordpress all fall into the 'impossible' category. It is well-known that Facebook keeps data generated by its users even after they decide to delete their accounts - "For example, a friend may still have messages from you even after you delete your account. That information remains after you delete your account," states Facebook's Help Center - making it exceedingly difficult to properly delete the multitudes of data that any given user may have shared on the social network in his or her lifetime.

While reactive privacy and surveillance rights are important, the right to nonparticipation is a formalized a priori version of these rights; it encapsulates them and other rights by stating that individuals have the right to refuse to participate in data capturing processes that are hidden from them. Privacy, security, surveillance, and other forms of rights fall under the category of the right to nonparticipation, which should be viewed as a universal right that is granted to global digital citizens. Policy can help grant such rights to users over large non-Statal organizations. This is especially true for the United States, which currently lacks any significant body of judicial decisions concerning the Federal Trade Commission's enforcement of privacy practices (Solove \& Hartzog, 2014).

\section{Towards a Policy for Global Digital Citizenship}

A GDC policy can be formulated which protects the rights of global digital citizens in terms of nonparticipation and indicates the information rights that global digital citizens are giving up when they participate in online ICTs. Policies that enforce the right to nonparticipation will become increasingly needed as problems around net neutrality, corporate data mining, and government surveillance continue to grow (McKee, 2011). Of course, many difficult problems remain. Who is to enforce these rights? Where is the line between citizenship, global citizenship, digital citizenship, and global digital citizenship? Who is to be held accountable? Such questions must be addressed if there is to be a governing body to enforce a right to nonparticipation policy.

Two well-known examples offer themselves as early candidates for policies reflecting the rights of global digital citizens, including the right to nonparticipation: Pentland's (2009) New Deal on Data and the European Union's General Data Protection Regulation. They are, however, not without shortcomings. Most stem from the notion that public data is inherently good, even if this data belongs to private citizens. Rather, the right to nonparticipation should be seen as a way to maintain a degree of obscurity set by the individual user in the face of algorithmic ICTs. Selinger and Hartzog (2014) argue that privacy debates can be better understood as concern over losing obscurity rather than as an issue of private versus public information. Further, Ausloos (2012) suggests that such policies should "restore the balance by taking into account the dynamic nature of 'personal 
data' and allowing the data subject to adapt its position over time" (p. 151). Recalling Solove (2007), private information is not simply a matter of 'good' or 'bad' information, but rather a question of acknowledging the spectrum of rights of global digital citizens over their nonparticipation.

\section{New Deal on Data}

The New Deal on Data (Pentland, 2009) suggests that individuals should be the legal owners of their data by adopting Old English Common Law and the three basic tenets of ownership (right of possession, use, and disposal). This has influenced companies such as Google, who are "coming under pressure to conform to the higher standards being imposed on regulated industries" (Pentland, 2014, p. 183). Google has taken steps to address privacy issues by creating the Google Dashboard (www.google.com/dashboard) and the Data Liberation Front (www.dataliberation.org).

One of the shortcomings of the New Deal on Data is its emphasis on keeping a large amount of data for prosperity in something like a data commons. While the New Deal on Data's focus is on securing ownership of data for the individual user, the New Deal on Data also emphasizes the benefits of efficient and safe data sharing. Pentland (2014) describes the Trento Living Lab, "a pilot for a New Deal on Data and for new ways to give users control of the use of their personal data" (p. 188). They "explore different techniques and methodologies to protect the users' privacy while at the same time being allowed to use their personal data to generate a useful data commons" (p. 188). In this way, the New Deal on Data is not only about protecting data rights but also about using personal data for good causes such as health research. Pentland (2014) writes that "our data are worth more when shared, because they can inform improvements in systems such as public health, transportation, and government" (p. 178). However, non-Statal organizations such as Google should not be the arbiters of data conflicts in a trust framework.

Nissenbaum (2010, p. 87-88) offers three reasons why non-Statal organizations should not be the arbiters of privacy protections. First, there is no incentive for non-Statal organizations to allow desertion since the value of information lies in its completeness and abundance. Second, non-Statal organizations typically endorse choice, yet this would be blocked if users were allowed to simply stop choosing what to do with their data. Third, it is difficult to allow customers to knowingly choose their own level of surveillance via the non-Statal organization's ICTs, since they may not be familiar with the inner workings of those ICTs or their privacy functions. As such, the New Deal on Data does not go far enough in preventing the data capture of non-Statal organizations. While increased data sharing is beneficial for fields such as health research, such benefits should not be viewed as outweighing protections against data capture, a point on which the New Deal on Data falls short. Non-Statal organizations use big data techniques which "compromises socially shared information [...] democratized big data can turn seemingly harmless disclosures into potent privacy problems" (Hartzog \& Selinger, 2013). Mundane tweets, for example, sent out by an individual may be harnessed and used in ways that that individual might not have anticipated or approved.

\section{General Data Protection Regulation}

The European Union's General Data Protection Regulation (GDPR) offers a number of measures that can be related to a global right to nonparticipation. It is one of the most comprehensive data protection acts that exist in the world today. Among the many recommendations, the following points contained in the GDPR and summarized by Zeiter (2014) are most relevant to the right to nonparticipation and may be adapted globally. First, 'the right to erasure' means that personal data "will generally have to be deleted when the data is no longer needed, the data subject has withdrawn his or her consent, the storage period has ended, or the data has been processed illegally" (p. 21). Second, 'the right to access and to obtain data for the data subject' means that "data subjects will be able to request a copy of personal data being processed in a format usable by this person and be able to transmit it electronically to another processing system" (p. 23-24). Lastly, 'data 
protection by design and by default' means that "data privacy standards be already designed into the development of new business processes for products and services, and that privacy settings are generally set at a high level by default" (p. 25). Zeiter successfully contextualizes the GDPR for American companies, showing that the positive outcomes of the GDPR may be implemented globally. What the current article proposes is that such laws as those represented in the GDPR might take on a global application and thus be applied to every global digital citizen.

Perhaps most relevant to the right to nonparticipation, the right to erasure - also known as the 'right to be forgotten' - is another way that policies approaching something like the right to nonparticipation are beginning to be discussed concretely in major legal arenas (Floridi et al, 2015). The right to be forgotten can be interpreted as a minor version of the right to nonparticipation in an online context. However, it is not entirely correct that the right is "a way to give (back) individuals control over their personal data and make the consent regime more effective" (Ausloos, 2012). This is only minimally true. The problem with the ruling in the case of the right to be forgotten (a ruling which stated that, in Europe, Google had to remove links to individual's private information if that information is harmful and no longer relevant, with a number of added caveats) is that corporations should not be the moral arbiters of what deserves to be deleted on the Internet.

To implement the necessary changes, Google's Advisory Council reported on the findings of the ruling. Committee members included Luciano Floridi (Professor of Philosophy and Ethics of Information at the University of Oxford), Sylvie Kauffman (editorial director at the French newspaper Le Monde), Lidia Kolucka-Zuk (former Executive Director for the Warsaw-based Trust for Civil Society in Central and Eastern Europe), Frank La Rue (former Executive Director for the Warsaw-based Trust for Civil Society in Central and Eastern Europe), Sabine Leutheusser-Schnarrenberger (member of the German parliament for over 23 years ), José-Luis Piñar (Doctor in Law), Peggy Valcke (research professor at KU Leuven in Belgium), and Jimmy Wales (Founder and Chair Emeritus, Board of Trustees, Wikimedia Foundation). Information about the advisory committee, including their report, can be found at https://www.google.com/advisorycouncil/).

One of the interesting findings contained in the report is that a non-Statal organization like Google should not act as the authority who decides what should or should not be allowed on the Internet. Further, as Ausloos (2012) notes, the right's scope "should be limited to situations in which the data subject provided his or her unambiguous consent"- the non-Statal organization "almost always fails to offer true choice and control to data subjects" (p. 151). Other problems remain. Ausloos (2012) states that the right to be forgotten

only comes ex post [...] [it] is very hard to effectively implement in practice and only postpones the illusion of choice. [...] Despite the rising awareness of individuals and efforts such as minimisation and anonymisation, data subjects still often disagree with unforeseen types of processing and/or simply change their mind. The current regulatory framework does not provide individuals with a satisfactory level of control over their data in the information society (p. 152).

The GDPR suffers from some of the same shortcomings as the New Deal on Data, particularly concerning the right to be forgotten. It places responsibility on the part of the non-Statal organization. The correct route would be to implement policies which request that non-Statal organizations construct ICTs with simple and clear mechanisms that enable users to choose nonparticipation when it comes to sharing their data. In other cases, a global policy entity should enforce policies like the right to nonpariticpation.

\section{Conclusion}

In the future, important work in information ethics (Floridi, 2013) can help facilitate inquiries into new policies and the new rights that are owed to global digital citizens. Policies must be developed that aim to protect the rights of global digital citizens and which offer the option of nonparticipation as a fundamental right to data subjects. Nonparticipation will be an important right for the new figure of the global digital citizen who must be viewed as not connected to a national entity and who is frequently denied their rights when international 
corporations extract data from them. Individuals are their data and thus should be aware that nonparticipation in the process of data extraction is one of their fundamental rights. Policy researchers should create opportunities for incorporating nonparticipation into the policies and best practices of businesses and their technologies.

\section{References}

Abdi, A. A., \& Shultz, L. eds. (2008). Educating for Human Rights and Global Citizenship. Albany: State University of New York Press.

Agre, P. E. (1999). "The Architecture of Identity: Embedding Privacy in Market Institutions. "Information, Communication \& Society. 2 (1). Spring. 1-25.

Andreotti, V. de O., \& de Souza. L. M. T. M. eds. (2012). Postcolonial Perspectives on Global Citizenship Education. London: Routledge.

Arnstein, S. R. (1969). "A Ladder of Citizen Participation. "Journal of the American Planning Association 35 (4) $216-224$.

Ausloos, J. (2012). "The 'Right to be Forgotten' - Worth remembering?" Computer Law \& Security Review. 28. $143-152$.

Baudrillard, J. (2006). Simulacra and Simulation. Ann Arbor: The University of Michigan Press.

Bourdieu, P. (1994). "Rethinking the State: Genesis and Structure of the Bureaucratic Field." Trans. Loic J.D. Wacquant; Samar Parage. Sociological Theory. 12 (1). 1-18.

Cabrera, L. (2010). The Practice of Global Citizenship. Cambridge: Cambridge University Press.

Carter, A. ed. (2001). The Political Theory of Global Citizenship. London: Routledge.

Cerf, V. (2010). "Trust and the Internet." IEEE Internet Computing. September/October. 95-96.

Clark, A. (2010). The ABCs of Human Survival: A Paradigm for Global Citizenship. Edmonton: Athabasca University Press

Collins, M. (2008). Global Citizenship for Young Children. Los Angeles: Sage.

Custers, B., van der Hof, S., \& Schermer, B. (2014). "Privacy Expectations of Social Media Users: The Role of Informed Consent in Privacy Policies. "Policy \& Internet. 6 (3). 268-295.

Diamos, J. (1996). "Abdul-Rauf Is Calm In Face of Controversy," The New York Times. March 21. Accessed at http://www.nytimes.com/1996/03/21/sports/pro-basketball-abdul-rauf-is-calm-in-face-of-controversy.html

Depken, C. A. (2006). "Who Supports Internet Censorship?" First Monday. September. 11 (9). Accessed at http://firstmonday.org/ojs/index.php/fm/article/view/1390/1308\#d4

Floridi, L. (2013). The Ethics of Information. Oxford: Oxford University Press.

Floridi, L. (2014). "The Rise of the MASs" in Protection of Information and the Right to Privacy - A New Equilibrium?. ed. Luciano Floridi. Cham: Springer.

Floridi, L. ed. (2015). The Onlife Manifesto: Being Human in a Hyperconnected Era. Cham: Springer.

Floridi, L., Kauffman, S., Kolucka-Zuk, L., La Rue, F., Leutheusser-Schnarrenberger, S., Piñar, J-L., Valcke, P., Wales, J. (2015). The Advisory Council to Google on the Right to be Forgotten. Report. Accessed at https://drive.google.com/file/d/OB1UgZshetMd4cEI3Sj/vVOhNbDA/view

Gillespie, T. (2014). "The Relevance of Algorithms." in T. Gillespie, P. Boczkowski, \& K. Foot. eds. Media Technologies: Essays on Communication, Materiality, and Society. 167-194. Cambridge: MIT Press.

Gunkel, D. (2003). "Second Thoughts: Toward a Critique of the Digital Divide." New Media \& Society 5 (4), 499-522.

Hartzog, W. \& Selinger, E. (2013). "Big Data in Small Hands." Stanford Law Review Online. 66. 81-88. 
Hastings, P. K. (1956). "The Voter and the Non-Voter." American Journal of Sociology. 62 (3). 302-307.

Hahn, A. J. (1970). "Citizens in Local Politics: Nonparticipation and "Unrepresentation"." Journal of the Community Development Society. 1 (2).

Harbinja, E. (2014). "Virtual Worlds Players - Consumers or Citizens?" Internet Policy Review: Journal on Internet Regulation. 3 (4).

Harrington, C. B. (1984). "The Politics of Participation and Nonparticipation in Dispute Processes. "Law \& Policy. 6 (2). 203-230.

Haugestad, A. K., \& Wulfhorst, J. D. eds. (2004). Future as Fairness: Ecological Justice and Global Citizenship. Amsterdam: Rodopi.

Hillerbrand, R., \& Karlsson, R. (2008). Beyond the Global Village: Environmental Challenges Inspiring Global Citizenship. Freeland Witney: Inter-Disciplinary Press.

Hoffman, J. (2004). Citizenship Beyond the State. London: Sage.

Isin, E. \& Ruppert, E. (2015). Being Digital Citizens. London: Rowman \& Littlefield International.

Jeong, H. O. (2013). "From Civic Participation to Political Participation." VOLUNTAS: International Journal of Voluntary and Nonprofit Organizations. 24. 1138-1158.

Katz, J. (1997). "The Digital Citizen." WIRED. 5 (12).

Klein, J. G., Smith, N. C., \& John, A. (2004). "Why We Boycott: Consumer Motivations for Boycott Participation." Journal of Marketing. 68 (3) 92-109.

Kurbanoğlu, S., Špiranec, S., Grassian, E., Mizrachi, D., Catts, R. eds. (2014). Information Literacy: Lifelong Learning and Digital Citizenship in the 21st Century. Second European Conference, ECIL. Dubrovnik, Croatia, October 20-23, Proceedings.

Kurlansky, M. (2006). Nonviolence: The History of a Dangerous Idea. New York: Modern Library.

Latour, B. (2013). An Inquiry into Modes of Existence: An Anthropology of the Moderns. Cambridge: Harvard University Press.

Lipset, S. M. (1959). "Some Social Requisites of Democracy: Economic Development and Political Legitimacy." The American Political Science Review 53 (1) 69-105.

Lyon, D. (2002). "Everyday Surveillance: Personal Data and Social Classifications. "Information, Communication \& Society. 5 (2). 242-257.

Margetts, H. (2009). "The Internet and Public Policy." Policy \& Internet. 1 (1).

May, C. K. (2012). "Active Non-Participation among Local Natural Resource-Dependent Communities: The Case of North Carolina Fisheries Governance." Journal of Environmental Management (113) 407-416.

McKee, H. A. (2011). "Policy Matters Now and in the Future: Net Neutrality, Corporate Data Mining, and Government Surveillance." Computers and Composition. 28. 276-291.

McKelvey, F. (2014). "Algorithmic Media Need Democratic Methods: Why Publics Matter." Canadian Journal of Communication. 39. 597-613.

McIntyre-Mills, J. J. (2005). Global Citizenship and Social Movements. Amsterdam: Harwood Academic Publishers.

Mossberger, K., Tolbert, C. J., \& McNeal, R. S. (2008). Digital Citizenship: The Internet, Society, and Participation. Cambridge: MIT Press.

Monahan, T. (2015). "The Right to Hide? Anti-Surveillance Camouflage and the Aestheticization of Resistance." Communication and Critical/Cultural Studies. 12 (2). 159-178."

Musiani, F. (2013). "Governance by Algorithms. "Internet Policy Review: Journal on Internet Regulation. 2 (3).

Nissenbaum, H. (2010). Privacy in Context: Technology, Policy, and the Integrity of Social Life. Stanford: Stanford University Press. 
O'Byrne, D. J. (2003). The Dimensions of Global Citizenship: Political Identity Beyond the Nation-State. London: Frank Cass.

OToole, T., Marsh, D., \& Jones, S. (2003). "Political Literacy Cuts Both Ways: The Politics of Non-Participation Among Young People." The Political Quarterly. 74 (3). 349-360.

Park, Y-J. (2014). "A Broken System of Self-Regulation of Privacy Online? Surveillance, Control, and Limits of User Features in U.S. Websites. "Policy \& Internet. 6 (4) 360-376.

Pentland, A. (2009). "Reality Mining of Mobile Communications: Toward a New Deal on Data" in The Global Information Technology Report 2008-2009. Soumitra Dutta \& Irene Mia eds. World Economic Forum.

Pentland, A. (2014). Social Physics: How Good Ideas Spread-The Lessons from a New Science. New York: Penguin.

Purcell, K. \& Rainie, L. (2014). "Technology's Impact on Workers." Pew Research Center. Available at: http://www.pewInternet.org/2014/12/30/technologys-impact-on-workers/

Radu, R. \& Chenou, J-M. (2015). "Data Control and Digital Regulatory Space(s): Towards a New European Approach." Internet Policy Review: Journal on Internet Regulation. 4 (2).

Ribble, M. \& Bailey, G. (2011). Digital Citizenship in Schools: Nine Elements All Students Should Know. Eugene: International Society for Technology in Education.

Robinson, E. W. (2011). Democracy Beyond Athens: Popular Government in the Greek Classical Age. Cambridge: Cambridge University Press.

Schattschneider, E. E. (1960). The Semi-Sovereign People. New York: Holt, Rinehart \& Winston.

Schwartz, P. M. (1994). "Privacy and Participation: Personal Information and Public Sector Regulation in the United States." Iowa Law Review. 80. 553-618.

Selinger, E. \& Hartzog, W. (2014). "Obscurity and Privacy." Routledge Companion to Philosophy of Technology. London: Routledge.

Simondon, G. (2005). L'individuation à la lumière des notions de forme et d'information. Paris: Millon.

Solove, D. (2004). The Digital Person: Technology and Privacy in the Information Age. New York: New York University Press.

Solove, D. (2007). "'I've Got Nothing to Hide" and Other Misunderstandings of Privacy. "San Diego Law Review. 44. 745-772.

Solove, D. \& Hartzog, W. (2014). "The FTC and the New Common Law of Privacy." Columbia Law Review. 114. 583-676.

Soss, J. \& Jacobs, L. R. (2009). "The Place of Inequality: Non-participation in the American Polity. "Political Science Quarterly 124 (1) 95-125.

Svantesson, D. J. B. (2011). Fundamental Policy Considerations for the Regulation ofInternet Cross-Border Privacy Issues. "Policy \& Internet. (3) 3. 1-22.

Taylor, N. (2002). "State Surveillance and the Right to Privacy." Surveillance \& Society. 1 (1). 66-85.

Tichy, N. M., McGill, A. R., \& St. Clair, L. (1997). Corporate Global Citizenship: Doing Business in the Public Eye. San Francisco: The New Lexington Press.

Turow, Hennessy, \& Draper. (2015). The Tradeoff Fallacy: How Marketers Are Misrepresenting American Consumers And Opening Them Up to Exploitation. A Report from the Annenberg School for Communication, University of Pennsy/vania. Accessed at https://www.asc.upenn.edu/news-events/publications/tradeoff-fallacy-how-marketers-are-misrepresenting-american-consumers-and

Tully, J. (2014). On Global Citizenship: James Tully in Dialogue. London: Bloomsbury.

Vleugels, C., Verhenneman, G., Bannier, S. (2011). "Moving from Opt-Out to Opt-In? Online Information Disclosure and Privacy Policies in an Era of Personalisation." Journal of Electronic Governance. 4 (1/2). 156171.

Yousif, M. (2015). "The Rise of Data Capital." IEEE Cloud Computing. 4. 
Zeiter, A. (2014). The New General Data Protection Regulation of the EU and its Impact on IT Companies in the U.S. Stanford - Vienna Transatlantic Technology Law Forum. TTLF Working Papers, No. 20.

Zimmer, M. (2010). "'But the Data is Already Public": On the Ethics of Research in Facebook. "Ethics and Information Technology. 12. 313-325.

Zittrain, J. (2008). The Future of the Internet-And How to Stop It. New Haven: Yale University Press.

Zuboff, S. (2015). "Big Other: Surveillance Capitalism and the Prospects of an Information Civilization." Journal of Information Technology. 30. 75-89. 